\title{
CORRIGENDUM
}

\section{Genetic variation in phosphodiesterase (PDE) 7B in chronic lymphocytic leukemia: overview of genetic variants of cyclic nucleotide PDEs in human disease}

Ana M Peiró, Chih-Min Tang, Fiona Murray, Lingzhi Zhang, Loren M Brown, Daisy Chou, Laura Rassenti, Thomas J Kipps and Paul A Insel

Journal of Human Genetics (2013) 58, 494; doi:10.1038/jhg.2013.54

Correction to: Journal of Human Genetics (2011) 56, 676-681; doi:10.1038/jhg.2011.80; published online 4 August 2011

The authors of the above article noticed errors in publication of this paper (in September 2011 issue).

In the list of authors, incorrect middle initial was applied to Dr Kipps. The correct name should have read Thomas J Kipps and is now shown correctly above.
The $-347 \mathrm{C}>\mathrm{T}$ mutation presented in this manuscript should have been reported as a $-347 \mathrm{G}>\mathrm{A}$ mutation.

The authors apologize for these errors. 